\title{
SPECIES DIVERSITY OF SOIL FUNGI FROM A CORN PLANTATION AT ECHAGUE, PHILIPPINES
}

\author{
REY MARK GASCON TECSON ${ }^{* 1}$, FLORENDA C. BALLESTEROS-TEMANEL ${ }^{1,2}$ AND \\ JAMES KENNARD SANZ JACOB ${ }^{1}$ \\ ${ }^{1}$ Department of Biological Sciences, College of Arts and Sciences, Isabela State University, Echague, Isabela, Pbilippines \\ ${ }^{2}$ Research and Development, Isabela State University, Echague, Isabela, Pbilippines
}

Received 12 November 2020 /Accepted 1 September 2021

\begin{abstract}
Soil fungi are a critical component of the agroecosystems and provide ecological services affecting food and bioproduct production. Awareness of the composition and distribution of local species is necessary to maximize the productivity and sustainability of the agroecosystems. This study aimed at isolating fungi from the soil samples collected from a corn plantation at Echague, Isabela, morphologically defining, characterizing, and determining the diversity of fungal isolates species. Soil samples from five (5) different sampling units were collected and microbiological techniques were used to isolate the fungi. Identification was performed by morphological characterization of fungal isolates guided by taxonomic keys and textbooks. Fungal diversity was assessed using Simpson's indices of diversity. Sixteen (16) fungal isolates were found; 12 were known and four (4) were unidentified. Ten (10) species belong to the Ascomycota group, and two (2) belong to the Zygomycota class. The Aspergillus species dominated the region amongst all the species isolated and established. Aspergillus fumigatus and Aspergillus flavus are densely populated and well distributed. A potent biocontrol agent was also identified, namely Trichoderma barzianum and Trichoderma viride. The Mucor sp. and the Rhizopus stoloniferous, Zygomycota fungi, were also identified.
\end{abstract}

Keywords: cornfield, morphological identification, soil fungi, species diversity

\section{INTRODUCTION}

Agroecosystems are a subset of a traditional ecosystem that lies within the agricultural human activity. These are natural habitats modified for the manufacture of food and other agricultural goods. It is also the most intensively managed and, hence, also the most disturbed ecosystem on Earth (Lemaire et al. 2008; Vandermeer 2011). One form of an agroecosystem is a corn plantation. Maize is one of the Philippines' most important staple crops. In exploiting agricultural capital it ranks second to rice. It is not only used for human consumption but also for animal feed and industrial uses, and is, therefore, a crucial crop in the growth of the livestock and manufacturing industries (Altoveros \& Borromeo 2007).

"Corresponding author, email: tecsonrmg1808@gmail.com
Isabela Province is one of the largest maize producers in the Cagayan Valley where the Echague Municipality is one of the province's maize producers. The town is often characterized as a large area of land that is known as a broad alluvial plain, flat, or almost level.

Soil fungi are a critical component of the agroecosystems and provide ecological services that affect food and bio-product production. Many of these main soil fungal species directly associate with plants and are determinants of the efficiency of the agroecosystems. Energy and matter fluxes through the soil decomposing subsystem, which is dominated by fungi and bacteria. Although invertebrates play a part in $\mathrm{N}$ fluxes, plants regulate largely the rhizosphere fungi by generating carbon and energy-rich compounds and bioactive phytochemicals (Ellouze et al. 2014). 
Given the significance of soil microorganisms in agroecosystem productivity, management of beneficial soil microbial diversity emerges as a new strategy for growing crops today. The efficient management of fungal capital is critical to maximizing agricultural ecosystem production and sustainability. Therefore, benchmark information must be generated on the occurrence and distribution of soil fungi. Awareness of the composition and distribution of local species is important if indigenous fungi communities in the soil are to be handled in a way that optimizes the productivity and sustainability of agricultural ecosystems. Studies on the determination of microbiota and mycoflora of soils collected from agroecosystems or agricultural lands in Isabela, Philippines, have also been inadequate. Thus, the research was conducted to determine soil fungal species and its diversity from a corn plantation in Annafunan, Echague, Isabela.

\section{MATERIALS AND METHODS}

\section{Selection of Study Area}

The study area was chosen based on the following criteria: the major maize growing area, peace and order, and accessibility to any reasonable means of transport. With these parameters, Barangay Annafunan $\left(16.7111^{\circ} \mathrm{N}\right.$, $\left.121.7224^{\circ} \mathrm{E}\right)$ was selected.

\section{Collection and Analysis of Soil Samples}

\section{Establishment of sampling points}

Sampling points were established using the Grid Cell Sampling method with modification (Ackerson 2018). The cornfield has a land area of $14,344 \mathrm{~m}^{2}$ (1.4 ha) and a sample size of $10,072.14 \mathrm{~m}^{2}$ was used for sample collection. It was split into 50 quadratic grids. The sampling points for soil sample collection were chosen at random.

\section{Collection of soil samples}

The soil samples were collected during the month of February after their cropping cycle from the selected cell grid numbers in the study area. Soil samples were collected at a radius of 12 inches at the center of the selected cell grid.
At a depth of $20 \mathrm{~cm}$, samples were collected using a sterilized spatula and placed in a polypropylene bag. Collected samples were taken to the laboratory for analysis.

\section{Analysis of soil samples}

Samples were milled and sieved twice in the laboratory to extract big stones and debris to obtain finer soil samples. The soil samples were physically and chemically analyzed. To determine the $\mathrm{pH}$, nitrogen $(\mathrm{N})$, phosphorus $(\mathrm{P})$, and potassium $(\mathrm{K})$ content of the soil samples, chemical analysis using different soil analysis methods were performed at the DA-CVRC Soils Laboratory, San Felipe, Ilagan City, Isabela. The potentiometric test was used to measure the $\mathrm{pH}$ of the soil, the $\mathrm{N}$ content of the soil was measured by the Walkley and Black spectrophotometric test, the P content by the Olsen test, and the cold sulfur extraction test was used to measure the $\mathrm{K}$ content of the soil sample.

\section{Isolation of Soil Fungi}

The soil fungi were isolated using the following techniques:

\section{Serial dilution method}

For isolation, serial dilution up to $\mathrm{X} 10^{5}$ $(1: 100,000)$ was performed. For each soil sample, five (5) sterilized test tubes containing 9 $\mathrm{mL}$ of sterile water were prepared and numbered accordingly. Five (5) grams of soil samples were blended into a beaker with $25 \mathrm{ml}$ of sterile water. From the soil solution, using a pipette, $1 \mathrm{~mL}$ was drawn and added to the first test-tube labeled as $\mathrm{X} 10^{1}$. Then, from $\mathrm{X} 10^{1}$ dilution, $1 \mathrm{~mL}$ was drawn and added to the test tube labeled $\mathrm{X} 10^{2}$. The serial dilution process was repeated up to the fifth test tube labeled as $\mathrm{X} 10^{5}$. After this, $1 \mathrm{~mL}$ dilutions of $\mathrm{X} 10^{5}$ were poured into a Petri dish containing potato dextrose agar (PDA) and incubated for 5 days at room temperature (Toma \& Faqi-Abdulla 2012). When the mixed culture of fungi ramified, each type of fungi was transferred to agar slants using for pure culture.

\section{3-point inoculation technique}

Using a 3-point inoculation technique, pure fungi isolates were inoculated where three 
mycelia inoculums were put equidistantly from each other in two (2) different sterilized solid media: potato dextrose agar (PDA) and coconut water agar (CWA) for 7 days at room temperature.

\section{Agar block technique}

Inside the microwaveable dishes, damp tissue and U-shaped folded foil were positioned. Placed over the foil was a glass slide. Aseptically, using a sterile scalpel, the agar block with streptomycin was cut and positioned in the center of the sterile glass slide. Each fungal isolate was inoculated and covered with a coverslip. Specimens were observed under a microscope (in LPO and HPO) after seven days of incubation and were photographed for further morphological examination.

\section{Morphological \\ Identification \\ Characterization}

and

Morphologically, fungal isolates were classified according to their macroscopic and microscopic characteristics. Macromorphological features such as colony color and density, growth patterns, and textures were noted. Micromorphological characteristics such as conidial shape, hyphae morphology, and spore morphology were also observed. The taxonomic key to classification devised by Quimio \& Hanlin (1999) was used to facilitate the identification of fungi.

\section{Measuring Fungal Occurrence and Diversity Pattern}

The fungal occurrence was measured as to fungal density, frequency, and relative frequency. The following formula was used:

Fungal Density $=\frac{\text { Number of individual species A }}{\text { Unit area }}$

$\begin{array}{ll}\begin{array}{l}\text { Relative Frequency } \\ (\%)=\end{array} & \begin{array}{c}\text { Number of isolates for } \\ \text { each species }\end{array} \\ \text { Total number of isolates } & \times 100\end{array}$

Alpha-diversity was used to measure the diversity of Soil fungi in the study area. The following indices were used to determine species diversity:
1. Simpson's Diversity Indices

a. Simpson's Index (Simpson 1949) measures the probability that two individuals randomly selected from a sample will belong to the same species (or some category other than species). With this index, 0 represents infinite diversity, and 1 , no diversity. That is, the bigger the value of $\mathrm{D}$, the lower the diversity. This was determined by using the formula:

$$
\mathrm{D}=\frac{\sum \mathrm{n}(\mathrm{n}-1)}{\mathrm{N}(\mathrm{N}-1)}
$$

where:

$n_{i}$ - total number of organisms of a particular species

$N$ - total number of organisms of all species

b. Simpson's Index of Diversity (1 - D) which was obtained by deducting Simpson's Index (D) from 1. The value of this index also ranges between 0 and 1 , the greater the value, the greater the sample diversity. The index represents the probability that two individuals randomly selected from a sample will belong to different species.

\section{RESULTS AND DISCUSSION}

\section{Description of the Physical Characteristics of the Study Area}

The prevailing climate at the time of sample collection and organic matter content of soil samples were used to characterize the study area.

Data on prevailing climate at the time of sample collection was taken from the ISU Agricultural Meteorological Research Center of CVARRD Compound, Isabela State University, San Fabian, Echague, Isabela, Philippines. During the month and day of soil sampling, climatic data such as temperature, relative humidity, amount of rainfall, evaporation, and total minutes of bright sunshine were noted (Table 1). 
Table 1 Summary of climatic data for February 2018

\begin{tabular}{rl}
\hline Climatic Data & Average \\
\hline Temperature & \\
Minimum & $20.94^{\circ} \mathrm{C}$ \\
Maximum & $29.29^{\circ} \mathrm{C}$ \\
Relative Humidity & \\
$8: 00 \mathrm{AM}$ & $95 \%$ \\
2:00 PM & $75 \%$ \\
Rainfall & 2.9 mins \\
Evaporation & 2.9 mins \\
Bright sunshine & 251 minutes \\
\hline
\end{tabular}

The average temperature in the municipality during the month of the collection of the samples ranges from $20.94{ }^{\circ} \mathrm{C}$ to $29.29^{\circ} \mathrm{C}$ with $95 \%$ to $75 \%$ relative humidity from $8 \mathrm{AM}$ to 2 PM. The table also shows that the average amount of rainfall and evaporation was 2.9 mins, respectively. The average bright sunshine for the whole month is $251 \mathrm{~min}$. During the conduct of the study, it showed that the temperature ranges from $23.5^{\circ} \mathrm{C}$ to $31.1^{\circ} \mathrm{C}$ with $98 \%$ to $73 \%$ relative humidity. There was no recorded rainfall during the day of sample gathering. The evaporation was registered at 3.5 mins with 330 total minutes of bright sunshine.

The table shows the organic matter (OM) content of the soil samples as to nitrogen $(\mathrm{N})$, phosphorus $(\mathrm{P})$, and potassium $(\mathrm{K})$ as well as its $\mathrm{pH}$. Soil analysis shows that the soil samples collected in the study area are all acidic with $\mathrm{pH}$ ranging from 4.9 to 5.4 with an average $\mathrm{pH}$ level of 5.2. Of the soil samples, sample 3 was recorded as the most acidic. The average $\mathrm{N}$ content of the study area is $1.06 \%$, while the $\mathrm{P}$ content of the soil is estimated at an average of $19.78 \mathrm{ppm}$, and the average $\mathrm{K}$ content of the soil in the study area is $280.80 \mathrm{ppm}$.
The climatic condition for the month of sample collections was warm with a relatively high humidity indicating high humidity content and high free water vapor is present in the air. Based on soil analysis, the $\mathrm{pH}$ level shows that it is favorable and suitable for fungal growth because fungi grow in a substrate ranging from $4.0-8.5$ or sometimes $3.0-9.0$ with an optimum $\mathrm{pH}$ level of $5.0-7.0$.

Several fungi are acid-tolerant which grows at $\mathrm{pH} 2.0$ with an optimum $\mathrm{pH}$ level of $5.5-6.0$ (Rousk et al. 2010a; Rousk et al. 2010b). The result of soil analysis indicates that the sample region has a very high Nitrogen $(\mathrm{N})$ content of 0.65 percent to $1.41 \%$ (Horneck et al. 2011). It has also been shown to have medium phosphorus (P) content of $13.52 \mathrm{ppm}$ to 31.81 ppm. The potassium $(\mathrm{K})$ content was low at 88 ppm for soil samples 1 and high at $289 \mathrm{ppm}$ to $399 \mathrm{ppm}$ for other soil samples. Overall, the study area's abiotic environment, such as climate data and soil analysis obtained, showed that it was favorable and suitable for fungal growth and sporulation. This may also be due to the levels of precipitation and temperatures resulting in favorable humidity and moisture that lead to the growth of soil fungi in the study area.

\section{Taxonomic Account and Description of the Fungi Isolates}

The following are the fungi species isolated from the soil samples taken from a corn plantation at Echague, Isabela, Philippines with their taxonomic classification as shown in Table 3 with morphological and biological description.

Table 2 Soil analysis conducted at Ilagan Soils Laboratory

\begin{tabular}{ccccc}
\hline \multirow{2}{*}{ Soil sample } & $\mathrm{pH}$ & \multicolumn{3}{c}{ Organic Matter } \\
\cline { 3 - 5 } & & $\mathrm{N}(\%)$ & $\mathrm{P}(\mathrm{ppm})$ & $\mathrm{K}(\mathrm{ppm})$ \\
\hline 1 & 5.2 & 1.10 & 31.81 & 88 \\
2 & 5.2 & 0.65 & 13.52 & 399 \\
3 & 4.9 & 1.20 & 18.37 & 329 \\
4 & 5.4 & 0.96 & 17.53 & 289 \\
5 & 5.3 & 1.41 & 17.67 & $\mathbf{2 8 0 . 8 0}$ \\
\hline Mean & $\mathbf{5 . 2}$ & $\mathbf{1 . 0 6}$ & $\mathbf{1 9 . 7 8}$ & \\
\hline
\end{tabular}


Table 3 Soil fungi species composition of the study area

\begin{tabular}{|c|c|c|c|c|c|}
\hline Division & Class & Order & Family & Genus & Species \\
\hline Ascomycota & Eurotiomycetes & Eurotiales & Trichocomaceae & Aspergillus & $\begin{array}{l}\text { A. niger Teigh } \\
\text { A. flavus Link } \\
\text { A. fumigatus Fresen. } \\
\text { A. terreus Thom } \\
\text { Aspergillus } \mathrm{sp} \text {. \# } 18 \\
\text { Aspergillus } \mathrm{sp} \text {. \# } 21\end{array}$ \\
\hline & Sordariomycetes & Hypocreales & $\begin{array}{l}\text { Bionectariaceae } \\
\text { Hypocreaceae }\end{array}$ & $\begin{array}{l}\text { Penicillium } \\
\text { Gliocladium } \\
\text { Trichoderma }\end{array}$ & $\begin{array}{l}\text { Penicillium sp. Thom } \\
\text { G. roseum } \text { Bainer } \\
\text { T. barzianum Rifai } \\
\text { T. viride Pers. }\end{array}$ \\
\hline Zygomycota & Mucomycotina & Mucorales & Mucoraceae & $\begin{array}{l}\text { Mucor } \\
\text { Rhizopus }\end{array}$ & $\begin{array}{l}\text { Mucor sp. L. } \\
\text { R. stolonifer Thom }\end{array}$ \\
\hline
\end{tabular}

There were 12 taxa documented consisting of 10 Ascomycetes species and two (2) Zygomycetes species, while four (4) species were unidentified due to lack of defining morphological structures. Of the 12 identified fungi species, seven (7) species belong to the division Ascomycota, class Eurotiomycetes, order Eurotiales under the family Trichocomaceae. These species are Aspergillus niger Teigh, A. flavus Link, A. fumigatus Fresen., A. terreus Thom, Aspergillus sp. \#18, Aspergillus sp. \#21, and Penicillium sp. Thom. Two (2) families of the class Sordariomycetes, order Hypocreales were also noted in the study area: Bionectriaceae - Gliocladium roseum Bainer and Hypocreaceae - Trichoderma harzianum Rifai and T. viride Pers.

Two (2) species belong to the division Zygomycota, class Mucomycotina, order Mucorales under the family Mucoraceae. These species are Mucor sp. Fresen. and Rhizopus stolonifer Ehernb.

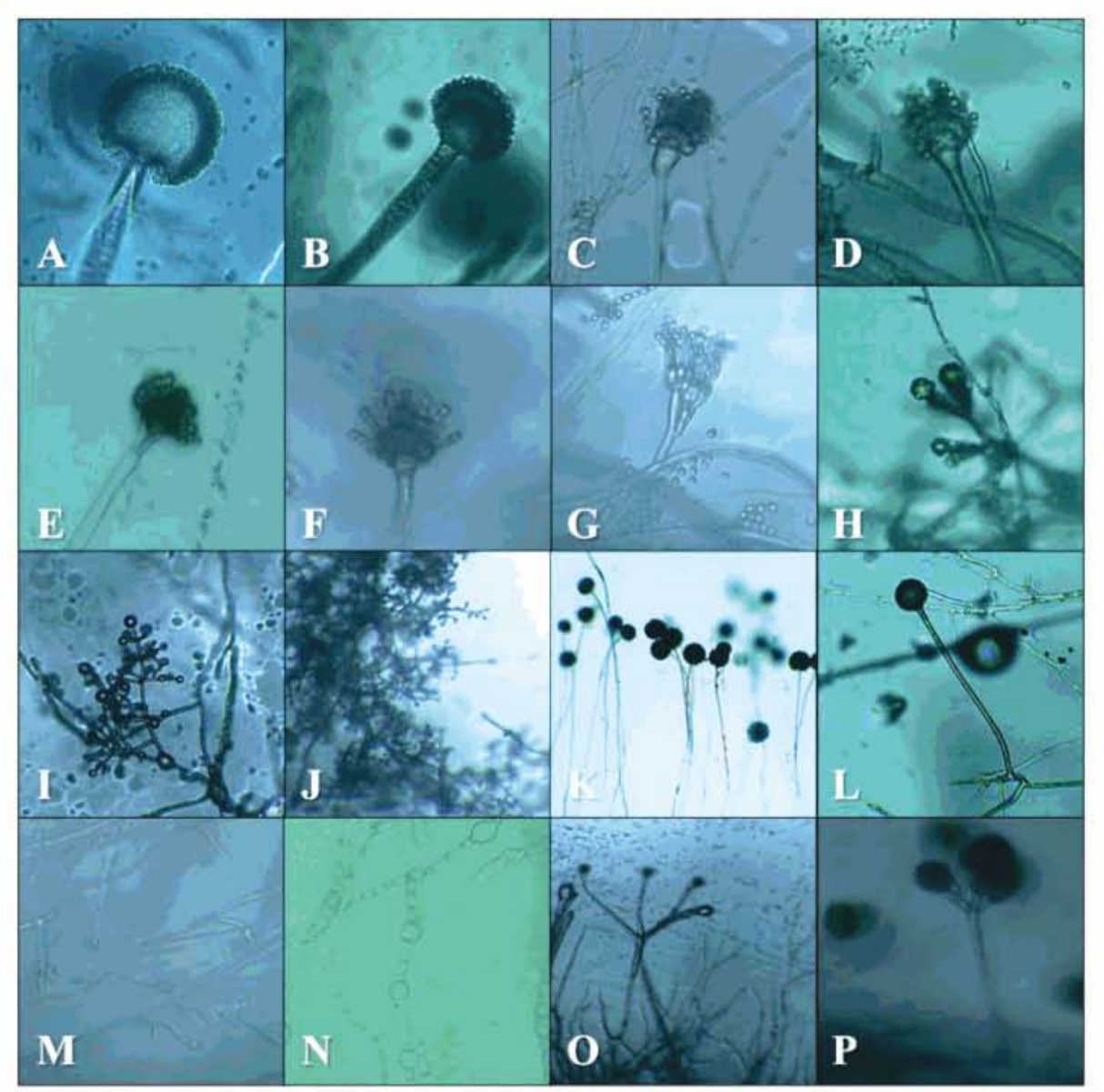

Figure 1 Microscopic Image under HPO: (A-F) Aspergillus (G) Penicillium (H) Gliocladium (I-J) Trichoderma (K) Mucor (L) Rhizopus (M-P) Unidentified species 
The Aspergillus niger (Fig. 1A) colony is black in color. Based on its colony morphology, $A$. niger exhibits filamentous margin and form with slightly umbonate elevation. Colonies show heavy sporulation on both media. Colonies on CWA show sporulation on the side forming a ring-like structure at its center while colonies on PDA showed a sporulated center towards the side. Microscopically, the conidial head is uniseriate and globose with rough walled conidia.

The Aspergillus flavus Link (Fig. 1B) colony is yellowish or olive-green color. Based on its colony morphology, $A$. flavus exhibits filamentous margin and form with slightly umbonate elevation on PDA and slightly crateriform on CWA. Colonies show heavy sporulation towards the sides that were surrounded by cottony-like structure mycelia. Microscopically, it shows radiate conidial heads with echinulate conidia.

Aspergillus fumigatus Fresen (Fig. 1C) colony is dark green to a lighter green color. Based on its colony morphology, A. fumigatus exhibits filamentous margin and form with slightly raised elevation. Colonies show heavy sporulation towards the sides surrounded by mycelia. Microscopically, it shows columnar conidial heads and uniseriate conidiogenous cells with smooth-walled stipes often green in the upper part and verrucose conidia.

Aspergillus terreus Thom (Fig. 1D) colony is yellowish-brown to a cinnamon-brown color. Based on its colony morphology, A. terreus exhibits undulate (wavy) margin and irregular form with slightly umbonate elevation. Colonies show heavy sporulation towards the sides showing more sporulation on PDA as compared to CWA. Microscopically, it shows densely columnar conidial heads are and biseriate conidiogenous cells with smooth-walled conidiophore and conidia.

Two species Aspergillus were also identified but were not narrowed down to species level due to lack of reliable literature for comparison of morphological structures. These species are shown in Figure 1E and Figure 1F.

Penicillium sp. Thom (Fig. 1G) colony differs from the beige blue and greyish blue color. Based on its colony morphology, Penicillium sp. exhibits the entire margin and circular form with umbonate elevation. Colonies show blue-green color due to heavy sporulation on PDA and greyish blue on CWA which are both surrounded by mycelia. Microscopically, it forms chains of spores (conidia) and brush-shaped conidiophores.

Gliocladium roseum Bainer (Fig. 1H) colony is white in color. Based on its colony morphology, G. roseum exhibits a filamentous margin and form with slightly umbonate elevation. Colonies show a cottony-like structure wherein G. roseum is larger on CWA than on PDA. Microscopically, it shows erect conidiospores with dense and has a brush-like structure where the conidia are single-celled and cylindrical.

Trichoderma harzianum Rifai (Fig. 1I) colony differs from different shades of green in color. Based on its colony morphology, T. harzianum exhibits filamentous margin and form with slightly convex elevation. Colonies show a completely ramified plate showing no gaps on and it shows darker green color at the center where their mycelia meet and leaving a circular hallow where they are inoculated on CWA. Microscopically, it forms sticky clumps of conidia rather than occurring in chains.

Trichoderma viride Pers (Fig. 1J) colony is green in color. Based on its colony morphology, $T$. viride exhibits undulate margin and irregular form with slightly raised elevation. Colonies show a completely ramified plate showing gaps between them on PDA and it shows that the colonies combine on CWA. Microscopically, it also forms sticky clumps of conidia rather than occurring in chains.

The Mucor sp. Fresen (Fig. 1K) colony is greyish brown to black color. Based on its colony morphology, Mucor sp. exhibited filamentous margin and form with flat elevation on PDA and slightly umbonate elevation on CWA. Colonies show pin-like structure with greyish black color due to heavy sporulation on PDA and it is physical appearance is the same as A. niger colonies with heavy sporulation at the center on CWA. Microscopically, it shows simple sporangiospores and apical form with globular sporangia that is elevated by a columnshaped columella.

Rhizopus stolonifer Ehrenb (Fig. 1L) colony is white or transparent in color. Based on its colony morphology, R. stolonifer exhibits filamentous margin and form with flat elevation. Colonies show a threadlike structure extending 
upward on PDA and CWA. Microscopically, it shows sporangia that are supported by a large apophysate columella atop a long stalk called sporangiophore.

Of the 16 taxa documented and isolated in the soil collected from the study area, there were four (4) unidentified species due to lack of literature published. These species are shown in Figure $1 \mathrm{M}$ to Figure 1P.

\section{The population of Fungal Species in the Study Area}

The total population of collected soil fungi in the study area was 163 fungal species. Of these, Aspergillus fumigatus showed the highest population with 54 species that occurred in all sampling units. This is followed by Aspergillus flavus with a population of 42 species which was also observed to be occurring in all the sampling points. The Mucor sp., Unidentified \#6, \#29, and \#32 showed the least population with a total of two (2) species respectively. It can also be noted that the most populous species in the area were under the genera of Aspergillus followed by Trichoderma.

Results showed that samples taken from the center of the cornfield are most abundant in soil fungi, whereas, $A$. fumigatus was relatively abundant in the field followed by $A$. flavus.

On the other hand, Mucor sp. was the least abundant. The abundance of $A$. fumigatus in the area attributed to its being a highly competitive member of compost microbiota where temperature, $\mathrm{pH}$, and nutrients may not be optimal for other organisms (van Heerden et al. 2002). Also, it presents a widespread environmental distribution that is capable to adapt diverse environmental conditions due to its thermotolerance and it can resist several sorts of environmental stresses (Oliveira \& Caramallo 2014; Rhodes 2006).

\section{Frequency and Relative Frequency of Soil Fungi Species}

The table of frequency and relative frequency of soil fungi species (as shown in Table 5) revealed that Aspergillus flavus $(12.20 \%)$ and Aspergillus fumigatus (12.20\%) showed the highest frequency followed by Aspergillus niger $(9.76 \%)$ The Mucor sp. $(2.44 \%)$, unidentified species \#11 (2.44\%), \#29 (2.44\%) and \#32 (2.44\%) exhibited the lowest frequency and relative frequency. A higher frequency indicates that a species is well distributed in the study area while a lower frequency indicates that it is concentrated only on the sampling unit or sampling area. Therefore, it shows that $A$. flavus and $A$. fumigatus are well distributed in the study area while Mucor sp., unidentified species \#11, $\# 29$ and \#32 are less distributed and are concentrated in a particular area in the study site.

Table 4 Population of the different fungi species present in the study area

\begin{tabular}{|c|c|c|c|c|c|c|}
\hline \multirow{2}{*}{ Species Name } & \multicolumn{5}{|c|}{ Sample Number } & \multirow{2}{*}{ Total } \\
\hline & 1 & 2 & 3 & 4 & 5 & \\
\hline Aspergillus niger & 2 & 2 & 1 & 0 & 3 & 8 \\
\hline Aspergillus flavus & 15 & 3 & 10 & 2 & 12 & 42 \\
\hline Aspergillus fumigatus. & 6 & 17 & 11 & 11 & 9 & 54 \\
\hline Aspergillus terreus & 0 & 0 & 2 & 0 & 3 & 5 \\
\hline Aspergillus sp. \# 21 & 0 & 0 & 2 & 2 & 0 & 4 \\
\hline Aspergillus sp. \# 18 & 0 & 0 & 6 & 0 & 0 & 6 \\
\hline Gliocladium roseum & 0 & 2 & 0 & 1 & 1 & 4 \\
\hline Mucorsp. & 1 & 0 & 1 & 0 & 0 & 2 \\
\hline Penicillium $\mathrm{sp}$. & 3 & 0 & 5 & 0 & 2 & 10 \\
\hline Rbizopus stolonifer: & 2 & 0 & 1 & 3 & 0 & 6 \\
\hline Trichoderma barzianum & 0 & 3 & 1 & 4 & 0 & 8 \\
\hline Trichoderma viride. & 1 & 0 & 2 & 1 & 0 & 4 \\
\hline Unidentified species \#11 & 0 & 4 & 0 & 0 & 0 & 4 \\
\hline Unidentified species \#6 & 0 & 0 & 1 & 0 & 1 & 2 \\
\hline Unidentified species \#29 & 0 & 0 & 0 & 2 & 0 & 2 \\
\hline Unidentified species \#32 & 0 & 0 & 0 & 2 & 0 & 2 \\
\hline Total: & 30 & 31 & 43 & 28 & 31 & 163 \\
\hline
\end{tabular}

Note: The unit for the fungal population is measured in $\mathrm{CFU} / \mathrm{mL}$. 
Table 5 Frequency and relative frequency of the different species present in the study area

\begin{tabular}{lcc}
\hline \multicolumn{1}{c}{ Species Name } & Frequency & Relative Frequency $(\%)$ \\
\hline Aspergillus niger & 4 & 9.76 \\
Aspergillus flavus & 5 & 12.20 \\
Aspergillus fumigatus. & 5 & 12.20 \\
Aspergillus terreus & 2 & 4.88 \\
Aspergillus sp. \# 21 & 2 & 4.88 \\
Aspergillus sp. \# 18 & 1 & 2.44 \\
Gliocladium roseum & 3 & 7.32 \\
Mucor sp. & 2 & 4.88 \\
Penicillium sp. & 3 & 7.32 \\
Rbizopus stolonifer. & 3 & 7.32 \\
Trichoderma barzianum & 3 & 7.32 \\
Trichoderma viride. & 3 & 7.32 \\
Unidentified species \#11 & 1 & 2.44 \\
Unidentified species \#6 & 2 & 4.88 \\
Unidentified species \#29 & 1 & 2.44 \\
Unidentified species \#32 & 1 & 2.44 \\
\hline
\end{tabular}

There was a total population density of 8.30 $\mathrm{CFU} / \mathrm{mL}(8.40 \%)$ of fungal isolates at a given area with a mean density of $1.66 \mathrm{CFU} / \mathrm{mL}$. Sampling unit 3 revealed the highest fungal density with a total of $2.2 \mathrm{CFU} / \mathrm{mL}(11 \%)$, while the least fungal density was shown on sampling unit 4 with a total of $1.4 \mathrm{CFU} / \mathrm{mL}$ $(7 \%)$ of fungal isolates. The Aspergillus fumigatus exhibited the highest fungal density with a total of $2.15 \mathrm{CFU} / \mathrm{mL}(54 \%)$ with a mean of 0.43 $\mathrm{CFU} / \mathrm{mL}$, followed by $A$. flavus with a total of $2.10 \mathrm{CFU} / \mathrm{mL}$ with a mean of $0.42 \mathrm{CFU} / \mathrm{mL}$, and lowest fungal density was shown in Rhizopus stolonifer and Trichoderma harzianum with a total fungal density of $0.05 \mathrm{CFU} / \mathrm{mL}(1 \%)$ with a mean density of $0.01 \mathrm{CFU} / \mathrm{mL}$ of fungal isolates. It shows that there is a high population density of $A$. fumigatus and $A$. flavus, whereas low population density in almost all the fungi species was observed. Also, genera under Aspergillus shows the densest species in the study area. A low population density may cause the extinction of the fungal species, which can be due to environmental factors such as disturbance, pollution, and habitat loss.

\section{Population Density and Relative Density}

The result of the study shows that there was a total of 16 fungal species isolated with a total of $163 \mathrm{CFU} / \mathrm{mL}$ of fungal population. It reveals that soil sample No. 3 that was collected almost at the center of the sampling area showed the highest fungal diversity with 0.84 value of computed Simpson's index of diversity (1-D). Notably that the soil sample No. 3 has the highest total number of fungal populations and the highest fungal density. Generally, it also reveals that species diversity in the study area is high with a 0.82 mean diversity value. Hence, the most diverse part of the study area is said to be at the center because most of the fungal communities were isolated and revealed a high population density in the study area. 
Table 6 Population density of the different species present in the study area

\begin{tabular}{|c|c|c|c|c|c|c|c|c|c|c|}
\hline \multirow{3}{*}{ Species Name } & \multicolumn{10}{|c|}{ Soil Samples } \\
\hline & \multicolumn{2}{|c|}{1} & \multicolumn{2}{|c|}{2} & \multicolumn{2}{|c|}{3} & \multicolumn{2}{|c|}{4} & \multicolumn{2}{|c|}{5} \\
\hline & $\mathrm{D}$ & $\mathrm{RD}$ & $\mathrm{D}$ & RD & D & $\mathrm{RD}$ & $\mathrm{D}$ & RD & $\mathrm{D}$ & RD \\
\hline Asperyillus niger & 0.10 & $10 \%$ & 0.10 & $10 \%$ & 0.05 & $5 \%$ & - & - & 0.15 & $15 \%$ \\
\hline Aspergillus flavus & 0.75 & $75 \%$ & 0.15 & $15 \%$ & 0.50 & $50 \%$ & 0.10 & $10 \%$ & 0.60 & $60 \%$ \\
\hline Aspergillus fumigatus & 0.30 & $30 \%$ & 0.85 & $85 \%$ & 0.55 & $55 \%$ & 0.55 & $55 \%$ & 0.45 & $45 \%$ \\
\hline Aspergillus terreus & - & - & - & - & 0.10 & $10 \%$ & - & - & 0.15 & $15 \%$ \\
\hline Aspergillus sp. \# 21 & - & - & - & - & 0.10 & $10 \%$ & - & - & - & - \\
\hline Aspergillus sp. \# 18 & - & - & - & - & 0.30 & $30 \%$ & - & - & - & - \\
\hline Gliocladium roseum & - & - & 0.10 & $10 \%$ & - & - & 0.05 & $5 \%$ & 0.05 & $5 \%$ \\
\hline Mucor sp. & 0.05 & $5 \%$ & - & - & 0.05 & $5 \%$ & - & - & - & - \\
\hline Penicillium sp. & 0.15 & $15 \%$ & - & - & 0.25 & $25 \%$ & - & - & 0.10 & $10 \%$ \\
\hline Rhizopus stolonifer & - & - & - & - & 0.05 & $5 \%$ & - & - & - & - \\
\hline Tricboderma barzianum & - & - & - & - & 0.05 & $5 \%$ & - & - & - & - \\
\hline Trichoderma viride & - & - & - & - & 0.10 & $10 \%$ & - & - & - & - \\
\hline Unidentified species \#11 & - & - & - & - & - & - & - & - & - & - \\
\hline Unidentified species \#6 & - & - & - & - & 0.05 & $5 \%$ & - & - & 0.05 & $5 \%$ \\
\hline Unidentified species \#29 & - & - & - & - & - & - & 0.10 & $10 \%$ & - & - \\
\hline Unidentified species \#32 & - & - & - & - & - & - & 0.10 & $10 \%$ & - & - \\
\hline Mean: & 1.5 & $8 \%$ & 1.6 & $8 \%$ & 2.2 & $11 \%$ & 1.4 & $7 \%$ & 1.6 & $8 \%$ \\
\hline
\end{tabular}

Notes: Legend: $\mathrm{D}=$ Density; $\mathrm{RD}=$ Relative Density (in percentage).

\section{Fungal Diversity}

The high diversity of fungi may be attributed to the time of sample gathering. Samples were collected after corn harvest, hence, lesser disturbances and there are no agricultural activities were conducted during collection time. The fallow period may allow microbial growth in the soil. Also, high fungal diversity may be attributed to the presence of corn waste such as corn cobs and other waste products after the corn harvest. Fungi are classified as decomposers for dead materials such as animals and plant waste. They also have this distinct characteristic as saprophytes, which means that they obtain food by absorbing dissolved organic material especially obtaining nourishment from the products of organic breakdown and decay. Higher fungal diversity and complex community enhance the decomposition rate of soil nutrients which promotes nutrient absorption and nutrient cycling (Hiscox et al. 2015; Kilvin et al. 2014; Yao et al. 2017).

Most of the fungal isolates were Aspergillus species wherein they are mostly pathogenic in nature producing aflatoxins. Aflatoxins are a group of naturally occurring mycotoxins that typically affect corns and peanuts which are ingredients use on both food and feed products (Williams et al. 2004). Colonization and contamination can occur in the crop field at harvest, during post-harvest operations, or when the crop is in storage. Also, man mycotoxins including aflatoxins can form during the growing stages of certain crops. Traditionally, fungal contamination caused by mycotoxins can be stopped and reduced growth by the use of fungicides in growing crops (Patel et al. 2015).

However, potential bio-control agent fungus was also isolated and identified in the form of Trichoderma harzianum and T. viride. Trichoderma species is a very effective biological means for plant disease management especially the soil born. It is a free-living fungus that is common in soil and root ecosystems. It is highly interactive in the root, soil, and foliar environments. It reduces growth, survival, or infections caused by pathogens by different mechanisms like competition, antibiosis, mycoparasitism, hyphal interactions, and enzyme secretion. Aside from being a potent biocontrol agent, Trichoderma is a plant growth promoter that solubilizes phosphates and micronutrients, and increases the number of deep roots of plants, thereby increasing the plant's ability to resist drought. Also, a biochemical elicitor of diseases by producing compounds to induce ethylene production, hypertensive responses, and other defense-related reactions in plant cultivars. And they play an important role in the bioremediation of soil that is contaminated by pesticides and herbicides (Sigh 2010). 
Table 7 Diversity of the different species present in the study area

\begin{tabular}{lccccc}
\hline \multirow{2}{*}{ Fungal Diversity Parameters } & \multicolumn{5}{c}{ Soil Sample } \\
\cline { 2 - 6 } & 1 & 2 & 3 & 4 & 5 \\
\hline Total number of Fungi Species (S) & 7 & 6 & 12 & 9 & 7 \\
Total number of Individuals/Population (N) & 30 & 31 & 43 & 28 & 31 \\
Simpson's Index (D) & 0.31 & 034 & 0.16 & 0.21 & 0.26 \\
Simpson's Index of Diversity (1-D) & 0.69 & 0.66 & 0.84 & 0.79 & 0.74 \\
\hline
\end{tabular}

Note: The total number of Individuals/Population is measured as CFU/mL.

\section{CONCLUSION}

Twelve fungal species were isolated and identified from the collected five soil samples in the study area. Most of the species were from the genera of Aspergillus, which exhibited the highest fungal population and density in the study area. Specifically, the Aspergillus fumigatus showed the highest fungal population and density in the area. The study area isolated a potent biocontrol agent for plant disease management, namely, Trichoderma barzianum and T. viride. The species diversity of fungal isolates in the study area is high. Therefore, the results of the foregoing study revealed that the study area or cornfield is upright for growing economically important food crops and other crops.

\section{ACKNOWLEDGEMENTS}

The authors would like to express gratitude to Mrs. Epifania Gonzaga, the owner of the cornfield for allowing and permitting the conduct of the study. To Ms. Dina M. Malangen for allowing us to coordinate with the owner of the field through her, and, to Ms. Judy Anne G. Ramiro for procurement of other materials and equipment needed in the study. Also, special appreciation to the faculty of the Department of Biological Science, Mrs. Helen C. Ramos, Mrs. Zarah A. Villalon, and Mr. Ron Patrick C. Campos for their guidance and technical contribution to the completion of the research study.

\section{REFERENCES}

Ackerson JP. 2018. Soil Sampling Guidelines. Purdue University: Purdue Extension; [updated 2018 Nov; cited 2020 Sept 14]. Available from:
https://www.extension.purdue.edu/extmedia/AY/ AY-368-w.pdf

Altoveros NC, Borromeo TH. 2007. The State of Plant Genetic Resources for Food and Agriculture of the Philippines. Philippines: Department of Agriculture and Bureau of Plant Industry.

Ellouze W, Esmaelli Taheri A, Bainard LD, Yang C, Bazghaleh N, Navarro-Borell A, Hamel C. 2014. Soil fungal resources in annual cropping systems and their potential for management. Bio Med Research International 53:18-24.

Horneck DA, Sullivan DM, Owen JS, Hart JM. 2011. Soil test interpretation guide. Ec 1478 Corvalis. Oregon State University Extension Services.

Hiscox J, Savoury M, Muller CT, Lindahl BD, Rogers HJ, Boddy L 2015. Priority effects during fungal diversity establishment in beech wood. ISME J 9:2246-60.

Kilvin SN, Winston GC, Goulden ML, Treseder KK. 2014. Environmental filtering effects of soil fungal diversity composition more than dispersal limitation at regional scales. Fungl Ecol 12:14-25.

Lemaire G, Carvalho O, Kronberg S, Recous S, 2018. Agroecosystem Diversity. Academic Press.

Oliver M, Caramallo R. 2014. Aspergillus fumigatus: a mere bioaerosol or a powerful biohazard? Nova Acta Cientifica Compostelana. Bioloxia 21:57-64.

Patel SV, Bosamia TC, Bhalani HN, Sigh P, Kumar A. 2015. Aflatoxins: Causes \& Effects. Agribios: A Monthly Magazine of Agricultural and Biological Sciences 13(09):140-2.

Quimio TH, Hanlin RT. 1999. Illustrated Genera and Species of Plant Pathogenic Fungi I the Tropics. College of Agriculture Publication Program.

Rhodes JC. 2006. Aspergillus fumigatus: Growth and Virulence. Medical Mycology 47:71-81.

Rousk J, Brookes PC, Baath E. 2010a. Investigating the mechanism for the opposing $\mathrm{pH}$-relaionships of fungal and bacterial growth in soil. Soil Biol Biochem 24:926-34.

Rousk J, Brookes PC, Baath E, Lauber CL, Lozupone C, Caporasa JG ... Fierer N. 2010b. Soil bacterial and fungal communities across a $\mathrm{pH}$ gradient in an arabe soil. ISME J 4:1-12. 
Sigh RK [Internet]. 2010. Trichoderma: A bio-control agent for management soil born diseases. Agropedis; [updated 2010 Jun 06; cited 2020 Sept 09]. Available from: http://agropedia.iitk.ac.in/ content/trichoderma-bio-control-agentmanagement-soil-born-diseases

Toma FM, Faqi Abdulla NQ. 2012. Isolation, Identification and Seasonal Distribution of Soil Borne Fungi in Different Aras of Erbil Governorate. J Adv Lab Res Biol 4(3):246-55.

Vandermeer JH. 2011. The Ecology of Agroecosystems. Jones and Bartlett Publisher. USA. van Heerden I, Cronje C, Swart SH, Kotze JM. 2002. Microbial, Chemical and Physical aspects of citrus waste composting. Bioresource Technology 81(1):71-6.

Williams SH, Philips TD, Jolly PE, Stiles JK, Jolly CM, Aggarval D. 2004. Human aflatoxicosis in developing countries: a review of toxicology, exposure, potential health consequences, and interventions. Am J Clin Nutr 80(05):1106-22.

Yao Q, Loi J, Yu Z, Li Y, Jin J, Liu X. 2017. Changes of bacterila community compositions after three years of biochar applications in black soil of Northeast, China. Appl Soil Ecol 113:11-21. 